\title{
Investigation on Mechanical Property Evaluation of Jute - Glass Fiber Reinforced Polyester
}

\author{
Sanjay M R*, Arpitha G R, B Yogesha \\ Department of Mechanical Engineering, Malnad College of Engineering, Hassan-573202, Karnataka, India
}

\begin{abstract}
Natural fibers have been investigated for use in polymers including flax, hemp, jute, sisal and banana. Recently there has been a greater leaning towards natural fiber reinforced polymers composites because these are environmental friendly and cost effective to synthetic fiber reinforced composites. In this work hand lay-up process is used to fabricate Jute-glass fiber reinforced polyester composites. Specimen preparation and testing was carried out as per ASTM standards. Composites were prepared using Jute - glass fibers of 50/50, 40/60 and 30/70 Weight fraction ratios and mechanical properties like tensile, impact and flexural strength of Jute - glass fiber reinforced polyester were evaluated. The results shows that tensile strength and impact Strength of 50\% Jute-50\% glass fiber composition is found to be better than the other two compositions and the flexural strength of $40 \%$ Jute- $60 \%$ glass fiber composition is found to be better than the remaining two compositions.
\end{abstract}

Keywords: Jute, glass fiber, Polyester, Hand Lay-up, Mechanical properties.

\section{Introduction}

A composite is a material which is manufactured by combining two or more dissimilar materials in such a way that the resultant material is endowed with properties superior to any of its original ones. FiberReinforced composites, owing to their enhanced properties, are normally applied in different fields like defence, aerospace, engineering applications, automotive, sports goods, etc. Hence natural fiber composites have gained increasing interest due to their eco-friendly nature. More work has been done by researchers based on these natural fibers. Naturally available fibers like jute, sisal, silk and coir are low cost, abundant and renewable, light in weight, with low density, higher toughness, and biodegradable. Natural fibres like jute have the potential to be used as a replacement for traditional reinforcement materials in composites for applications which requires high strength to weight ratio and further weight reduction.

Ramesh.et. al. [1] investigated on the hybrid composites and the effect of various parameters on the performance of the hybrid composites are subjected to mechanical testing such as tensile, flexural and impact test. The results indicated that the jute composite material shows maximum tensile strength and the jute composite material shows incorporation of sisal-jute fiber with GFRP can improve the properties and used as an alternate material for glass fiber reinforced polymer composites. Khan.et.al [2] Studied on the mechanical properties of woven jute fabric reinforced poly (L-lactic acid) composites. Mechanical tests were conducted on woven and non-woven jute fabric reinforced PLLA based composites. Woven structure exhibited excellent mechanical behaviour like tensile, flexural, and impact loadings compared to non-woven composite. Tensile, flexural, and impact strengths of WJF/PLLA composite were found higher at warp direction than weft direction.

Velmurugan.et.al [3] Studied on the tensile, bending, shear and impact properties of roof light resin, palmyra/glass fiber hybrid composites are studied. The mechanical properties increased due to hybridization. The properties are increasing continuously due to the addition of glass fiber. The studies are carried out for both skin core and dispersed type hybrid composites. The mechanical properties of fiber skin core construction are higher than the dispersed fiber construction. Boopalan.et.al [4] made a Comparative Study on the Mechanical Properties of Jute and Sisal Fiber Reinforced Polymer Composites and concludes that the mechanical properties of the jute fiber reinforced composites are higher than the sisal fiber reinforced Composites. Harish s.et.al. [5] developed coir composite material and they evaluated mechanical properties. Scanning electron micrographs obtained from fracture surfaces were used for a qualitative evaluation of the interfacial properties of coir /epoxy and compared with glass fibers. M. Muthuvel.et.al [6] investigated that the jute and glass fiber hybrid composite leads to the successful fabrication of Glass, Jute fiber and chopped fiber reinforced polyester composites with different fiber lengths is possible by simple hand lay-up technique. The mechanical properties of the composites like tensile, flexural and impact strength of the composites are also greatly influenced by the fiber lengths. Aleya Fardausy.et.al [7] studied that Jute-PVC composites demonstrate good mechanical strength and can be used as environmentally degradable thermoplastics. The fiber addition decreases bulk density of fabricated composites with increase of fiber addition. The tensile strength of jute-PVC composites increases with the increase in fiber addition. Water absorption property increases with the increase of soaking time because with the addition of fiber the composites were more prone to water. T. Munikenche Gowda.et.al [8] 
concluded that although the mechanical properties of jute/polyester composites do not possess strengths and module as high as those of other conventional composites, they can pocess better strengths than wood composites [9] and some plastics. Hence these composites could be considered for future materials use. Since the reinforcing materials eco-friendly, non-toxic, non-health hazardous, low in cost and easily available as compared to conventional fibres like glass, Kevlar, asbestos etc., the composites are a good substitute for wood in indoor applications such as shelves, partitions, wash basins [10] and table tops, and may also be suitable for outdoor uses such as roofing, drainage pipes, automobile components, electrical fittings as well as larger items such as lightweight fishing boats [11]. To as certain their suitability for outdoor applications, a few more tests are to be carried out to evolve the hydrothermal and weather resistance properties of these composites. M.A Kabir.et.al [12] studied that with the increase of fibre loading the values of flexural strength and charpy impact strength of composite material have been decreased. But the values of other mechanical properties remain almost the same. Satish Pujari.et.al [13] explores the potentiality of jute \&banana fiber composites, emphasizes both mechanical and physical properties and their chemical composition. The utilization and application of the cheaper goods in high performance appliance is possible with the help of this composite technology. Combining the higher properties of two different materials, lower manufacturing cost, versatility etc., makes them useful in various fields of engineering, high performance applications such as leisure and sporting goods, shipping industries, Aerospace etc. Hence, with this background, it is concluded that, the composites stand the most wanted technology in the fast growing current trend.

\subsection{Materials}

\section{Experimental Details}

Raw materials used in this experimental work are:

- Jute Fiber

- Glass Fiber Reinforced Polyester

- Isophthalic Polyester Resin

- Accelerator

- Catalyst

Jute Fiber: Jute is a long fiber, soft in nature and shiny plant fiber that can be spun into coarse and strong threads. It is produced from plant names called genus Corchorus. Jute is one of the lowest cost natural fibres, and is second one only to cotton in amount produced and variety of uses. Jute fibres are contains primarily of the plant materials such as cellulose and lignin. Jute grows in rainy season crop, growing best in warm, humid climates. As fig.1 shows Jute fiber was purchased from Basu Jutex, Kolkata.

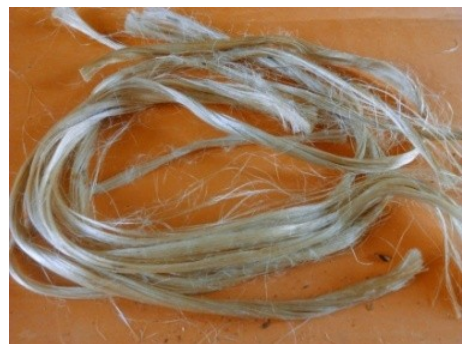

Fig.1 Jute Fiber

Glass Fiber Reinforced Polyester: Glass Fiber Reinforced Polyester is a fiber reinforced polymer made of a plastic matrix reinforced by fine fibers of glass. Fiber glass is a light in weight, extremely strong, and robust material. The glass fibre and chemicals are purchased from Insulation House, Bangalore, Karnataka. The Glass Fibre used for the fabrication is of unidirectional mat having $300 \mathrm{gsm}$.

Isophthalic Polyester Resin: The reaction of an organic acid with an alcohol results in the formation of the ester. By using a di-functional acid and a di-functional alcohol linear polyester is produced. Properties of the polyester can be varied by using different combinations of different di-acids and glycols. One such combination produces isopthalic resin. They are produced from isophthalic acids and are characterized by greater strength, heat resistance, toughness and flexibility. The acid groups are separated by one carbon of benzene ring. This increases the opportunity to produce polymers with great linearity and high molecular weight.

Cobalt Napthanate Accelerator: Potassium Octoate is often used as a synergistic promoter along with Cobalt in unsaturated polyester resin (UPR) systems. This product is designed as a partial replacement of cobalt soaps for use in gel coat and hand lay-up polyesters. The use of potassium helps obtain a lighter colored resin, offers 
reductions in costs, and minimizes gel time drift on aging. Cobalt $21 \%$ is often used in the production of prepromoted polyester resins to minimize drift particularly on storage.

Methyl Ethyl Ketone Peroxide Catalyst (MEKP): MEKP is organic peroxide, a high explosive similar to acetone peroxide. MEKP is a colourless, oily liquid, which initiates the Cross linking of unsaturated polyester resins used in glass-reinforced plastic, and casting.

2.2 Methodology: The step by step procedure to prepare composites and testing is shown in fig.2.

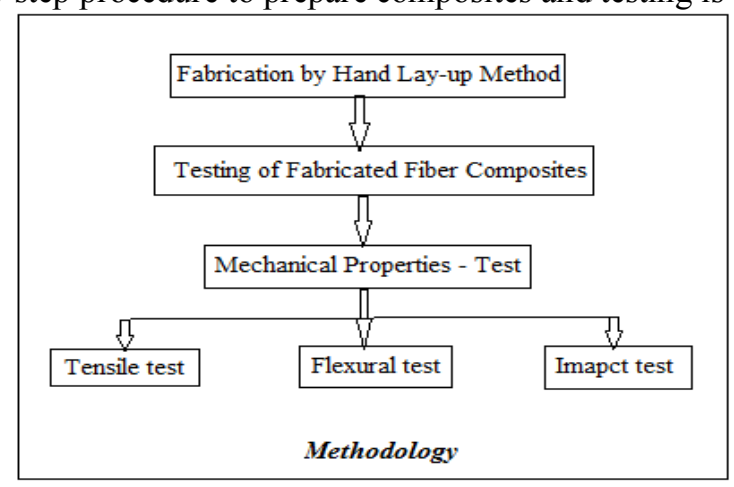

Fig. 2 Flow Chart

\subsubsection{Specimen Fabrication}

2.2.1.1 Mould Preparation: A mould with cavity dimensions $(260 \times 140 \times 10) \mathrm{mm}$ using stainless steel is prepared in the workshop for fabricating the composites (as shown in fig.3 \& fig.4).

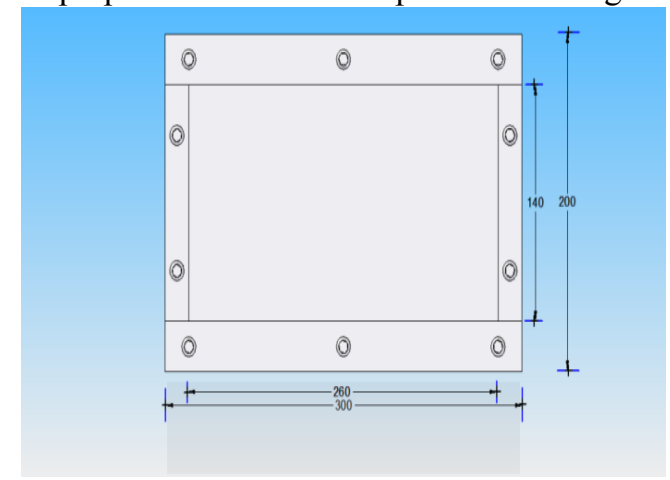

Fig. 3 Top view of the base plate

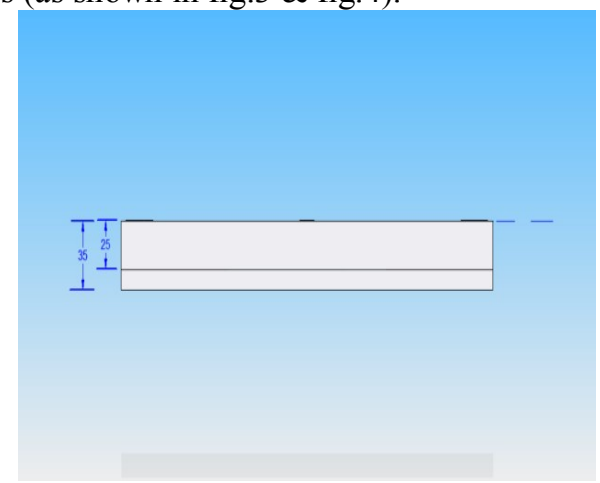

Fig. 4 Front view of the base plate

2.2.1.2 Fabrication Of Composite Specimen By Hand Layup Method: The composite materials used for the present investigation is fabricated by hand layup process. Chopped jute fibers of $260 \mathrm{~mm}$ length were used to prepare the specimen. The composite specimen consists of number of layers in which glass fiber layers and jute fiber layers are placed alternatively until we obtain required thickness. The layers of fibers are fabricated by adding the required amount of polyester resin. The glass fiber is mounted on the mould. The glass fiber reinforced polymer is then completely filled with polyester resin. The resin got mixed with glass fiber reinforced polymer, which may tend to dry up within 15-20 min. Before the resin gets dried, the second layer of jute fiber is mounted over the glass fiber reinforced polymer. The polyester resin applied is distributed to the entire surface by means of a roller. The air gaps formed between the layers during the processing are gently squeezed out. The processed composite which is placed in the base plate of mould is then closed by the top plate of mould, and pressure is applied over the mould and kept for several hours to get the perfect samples. After the composite material gets hardened completely, the composite material is taken out from the mould.

\subsubsection{Specimen Designation:}

The following Table.1 shows the different compositions of specimens.

Table 1 Specimen Designation

\begin{tabular}{|c|c|}
\hline Composites & Composition \\
\hline C1 & Jute $(50 \%)+$ GFRP $(50 \%)$ \\
\hline C2 & Jute $(40 \%)+$ GFRP $(60 \%)$ \\
\hline C3 & Jute $(30 \%)+$ GFRP $(70 \%)$ \\
\hline
\end{tabular}




\subsubsection{Mechanical Testing}

2.2.2.1 Tensile Test: The tensile strength of a material is the maximum amount of longitudinal stress that it can take before failure. The commonly used specimen for tensile test is prepared as per ASTM D638 standard of specimen dimension is $246 \times 29 \times 10 \mathrm{~mm}$ (as shown in fig.6). The testing process involves placing the test specimen in the testing machine and applying tension to it until it fractures. The tensile force is recorded as a function of the increase in gauge length. During the application of tension, the elongation of the gauge section is recorded against the applied force. The tensile test is performed in universal testing machine (UTM).
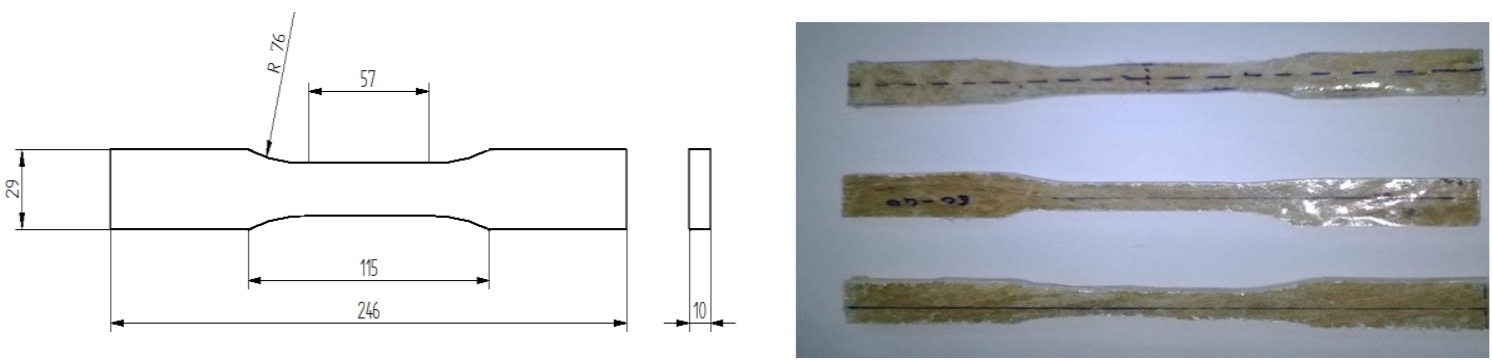

Fig. 6 Tensile Test Specimens

2.2.2.2 Flexural Test: The flexural specimens are prepared as per the ASTM D790 Standards as shown fig.7. All the specimens were of rectangular shape having dimension of 150x12.7x10 mm. The span length was $75 \mathrm{~mm}$.In composite materials specimen deflection is measured by the crosshead position. Test results include flexural strength and displacement. The testing process involves placing the test specimen in the universal testing machine and applying force to it until it fractures and breaks. The flexural test is performed on the Instron (UTM) 3382.
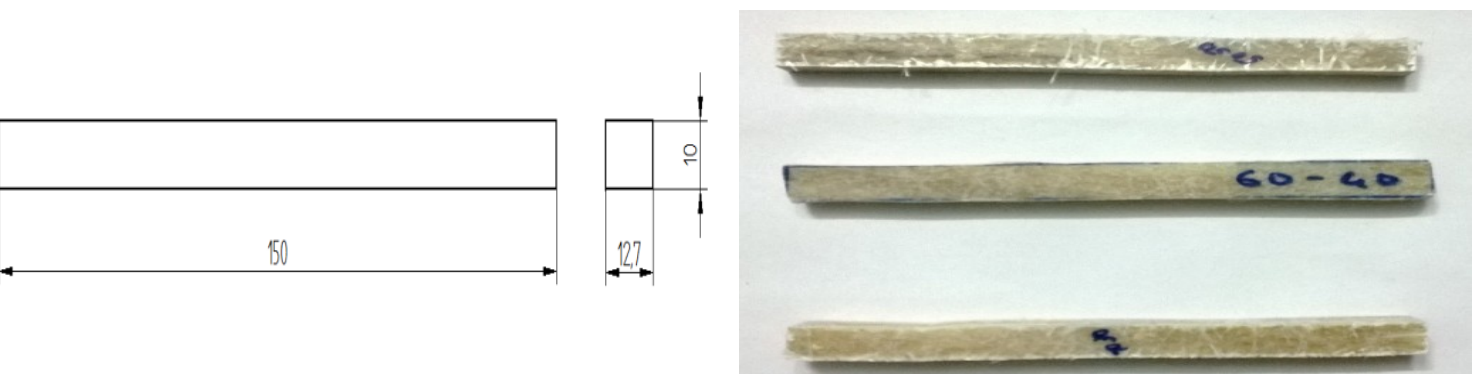

Fig.7 Impact Test Specimens

2.2.2.3 Impact Test: The impact test specimens are prepared according the ASTM A 370 standard as shown in fig 8.During the charpy impact testing process, the specimen must be loaded in the testing machine and allows the pendulum until it fractures or breaks. Using the impact test, the energy needed to break the material can be measured easily and can be used to measure the toughness of the material and the yield strength. The effect of strain rate on fracture and ductility of the material can be analyzed by using the impact test. Machine used: Tinius Olsen 504.
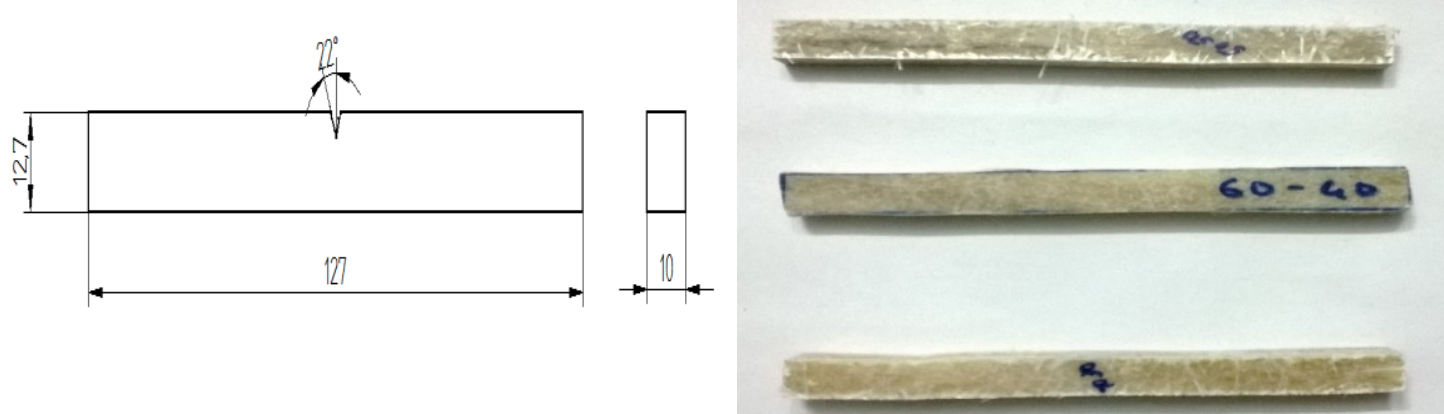

Fig.8 Impact Test Specimens 


\section{Results And Discussions}

The test results for the Tensile, Flexural and Impact testing for the three varieties of the hybrid composite samples are presented as in the Table.2.

Table 2 Experimental Results for Entire Test Conducted for Each Specimen

\begin{tabular}{|c|c|c|c|c|}
\hline Composition & Specimen & $\begin{array}{c}\text { Tensile Strength } \\
(\mathrm{MPa})\end{array}$ & Flexural Strength (MPa) & Impact Energy (Joules) \\
\hline \multirow{3}{*}{$\begin{array}{c}\text { C1 (50\% GF - 50\% } \\
\text { Jute) }\end{array}$} & 1 & 84.59 & 49.62 & 7.05 \\
\hline & 2 & 79.62 & 45.31 & 7.12 \\
\hline & 3 & 83.11 & 47.22 & 6.89 \\
\hline \multirow{3}{*}{$\begin{array}{c}\text { C2 (60\% GF - } 40 \% \\
\text { Jute) }\end{array}$} & 1 & 71.57 & 113.93 & 5.77 \\
\hline & 2 & 71.01 & 105.67 & 4.67 \\
\hline & 3 & 69.89 & 109.47 & 5.43 \\
\hline \multirow{3}{*}{$\begin{array}{c}\text { C3 (70\% GF - 30\% } \\
\text { Jute) }\end{array}$} & 1 & 56.04 & 84.87 & 6.15 \\
\hline & 2 & 58.38 & 82.17 & 5.98 \\
\hline & 3 & 54.58 & 84.13 & 5.7 \\
\hline
\end{tabular}

3.1 Tensile Properties: The different composite specimen samples are tested in the UTM and the samples are left to break till the ultimate tensile strength occurs. Stress-strain curve (fig.9, 10 \&11) is plotted for the determination of ultimate tensile strength and elastic modulus. The Tensile Strength comparison for different combinations of specimens is presented as in the fig. 12 .

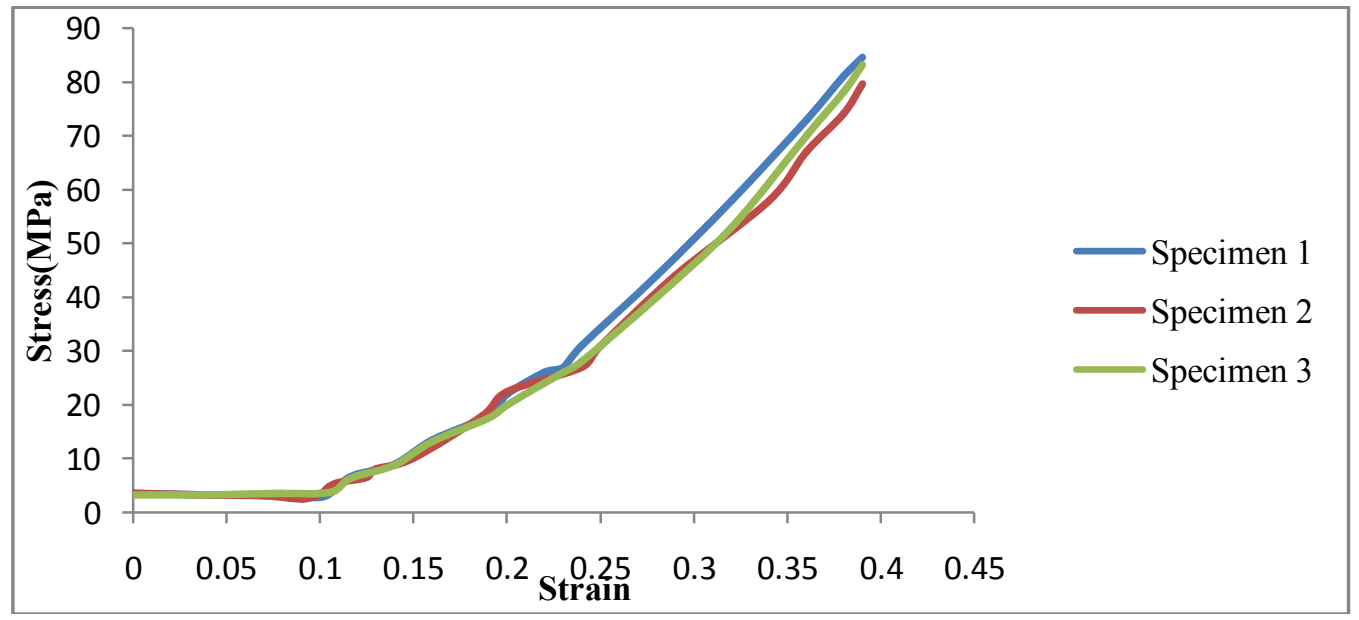

Fig.9 Stress - Strain diagram for composition 1

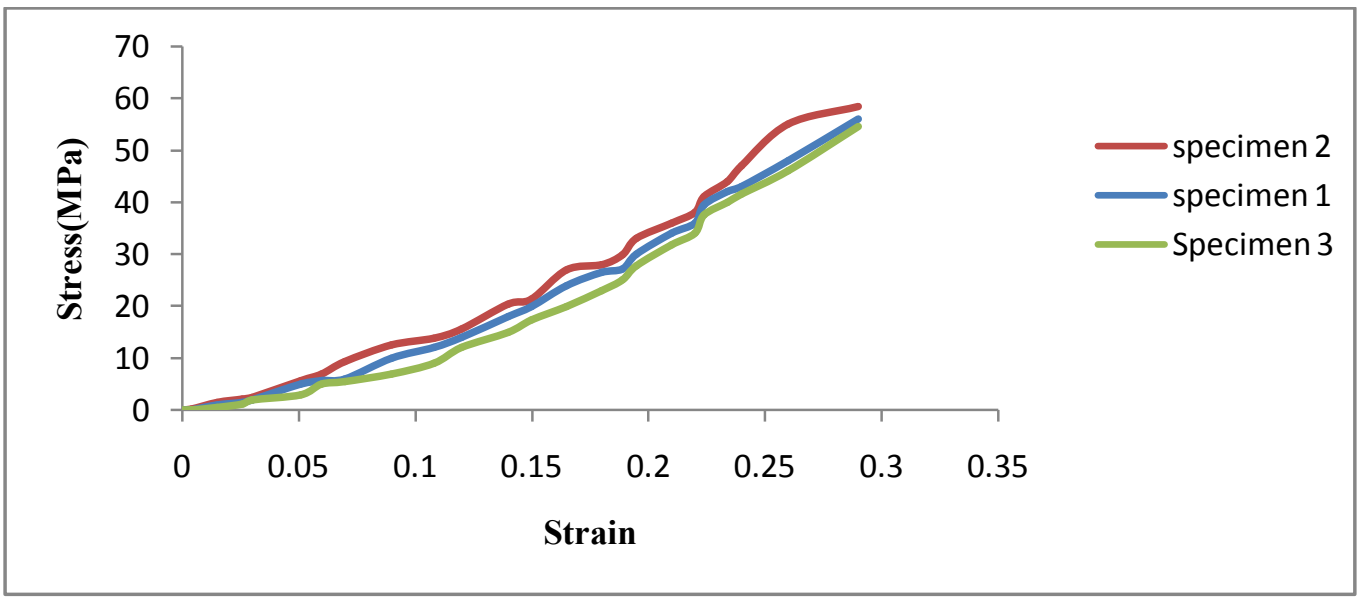

Fig.10 Stress - Strain diagram for composition 2 


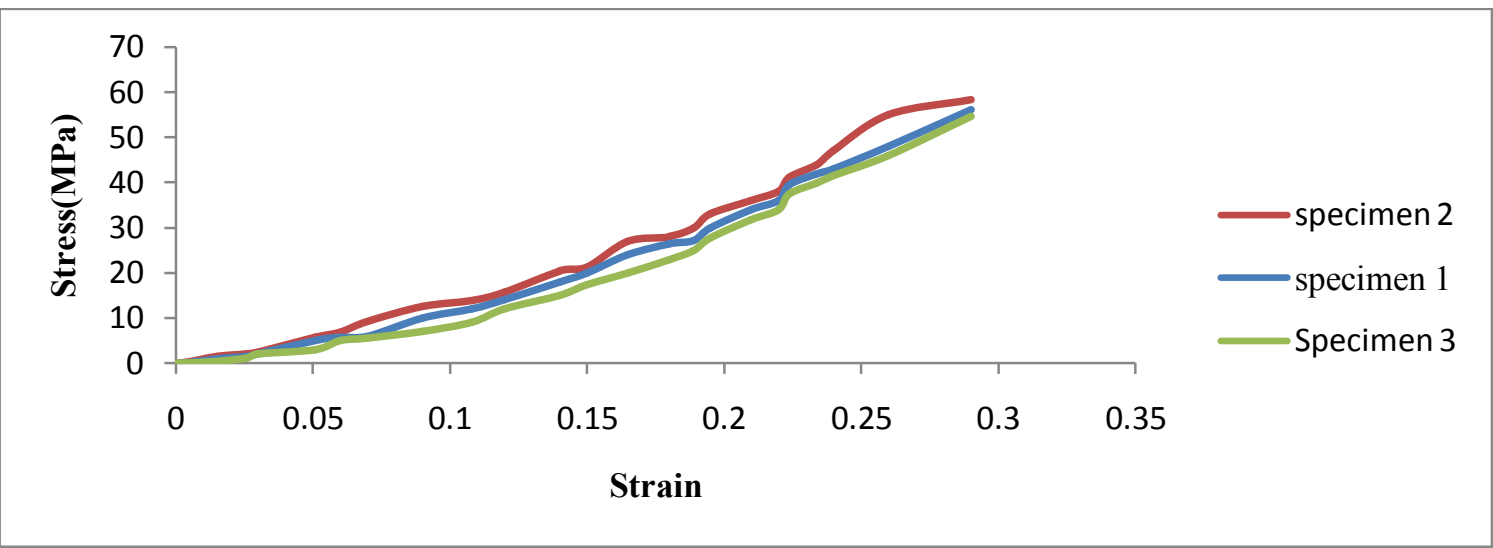

Fig.11 Stress - Strain diagram for composition 3

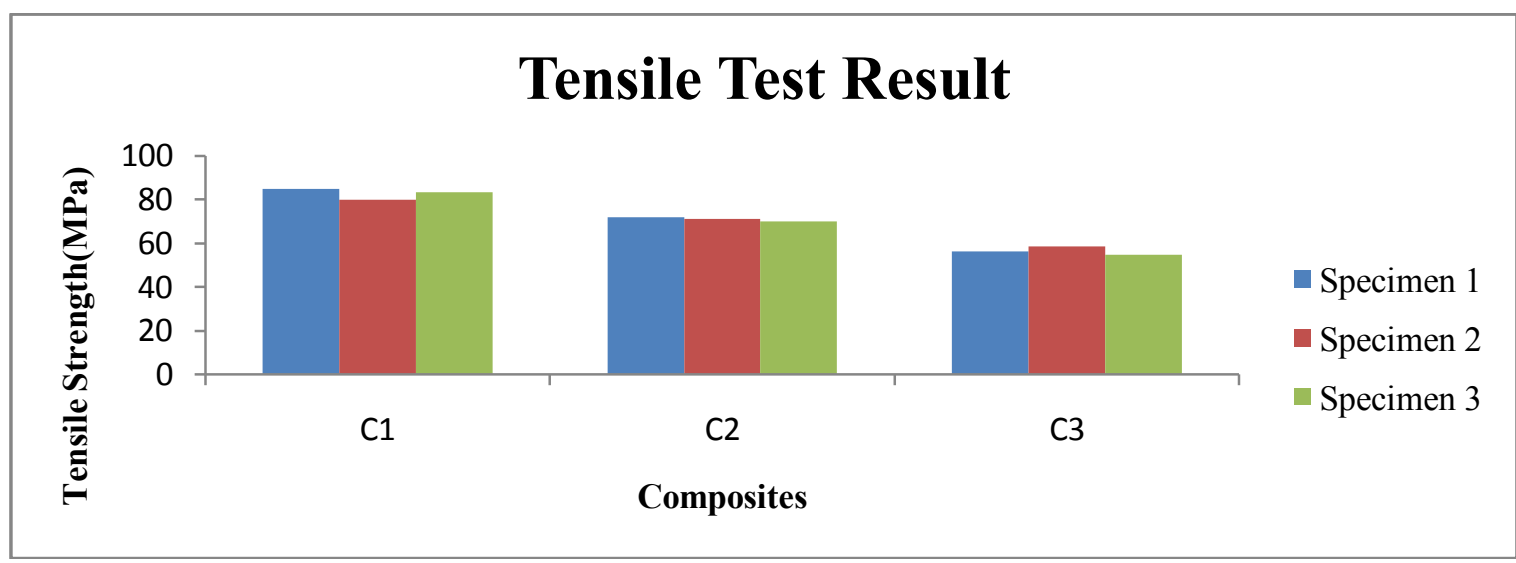

Fig.12 Tensile Strength comparison of different compositions

3.2 Flexural Properties: Three point bend test was carried out in an UTM machine in accordance with ASTM standard to measure the flexural strength of the composites. Load with respect to Cross Head Travel (fig.13, 14 \&15) is plotted for the determination of flexural strength. The different combination of composite specimen is presented as in the fig. 16.

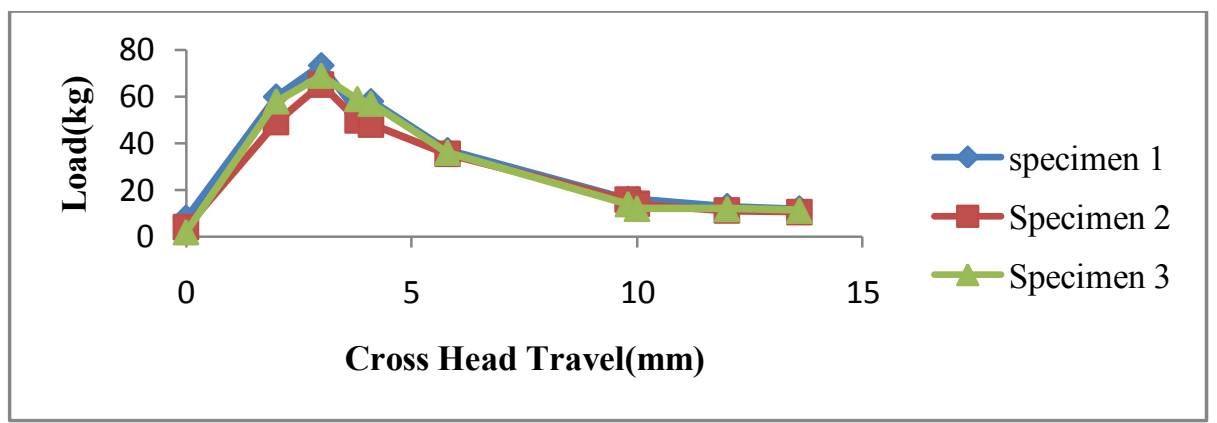

Fig.13 Load v/s Cross Head Travel graph for composition 1

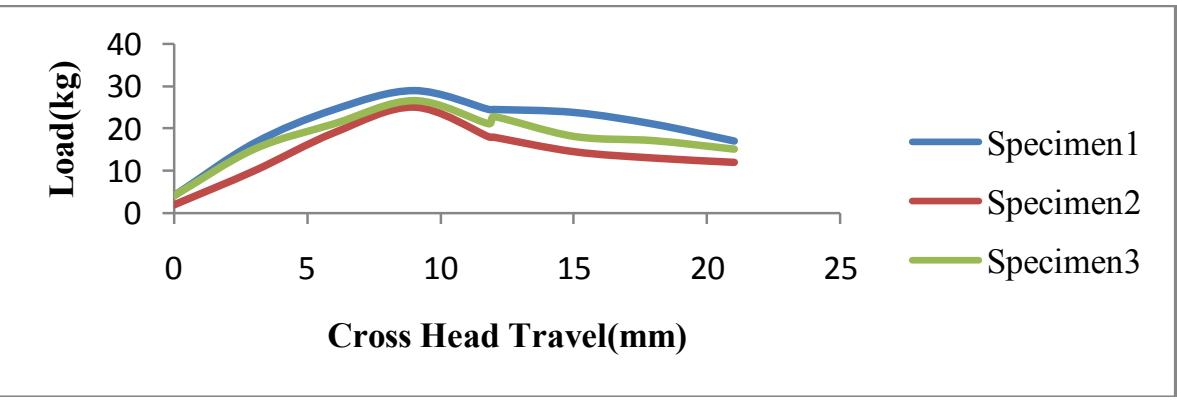

Fig.14 Load v/s Cross Head Travel graph for composition 2 


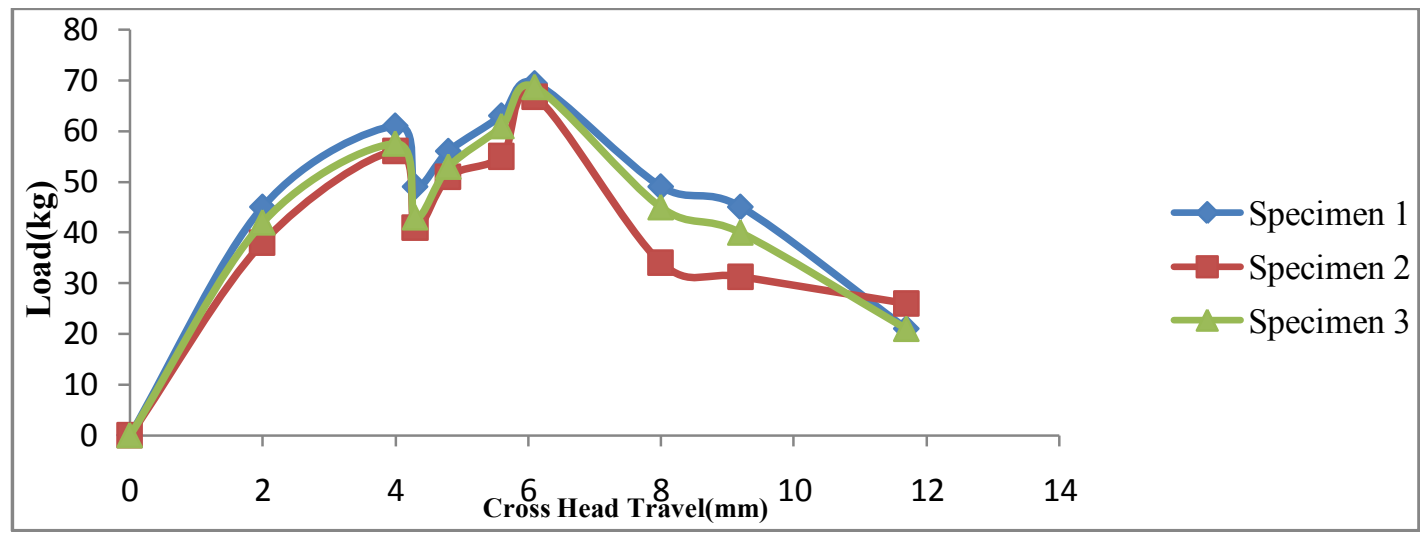

Fig.15 Load v/s Cross Head Travel graph for composition 3

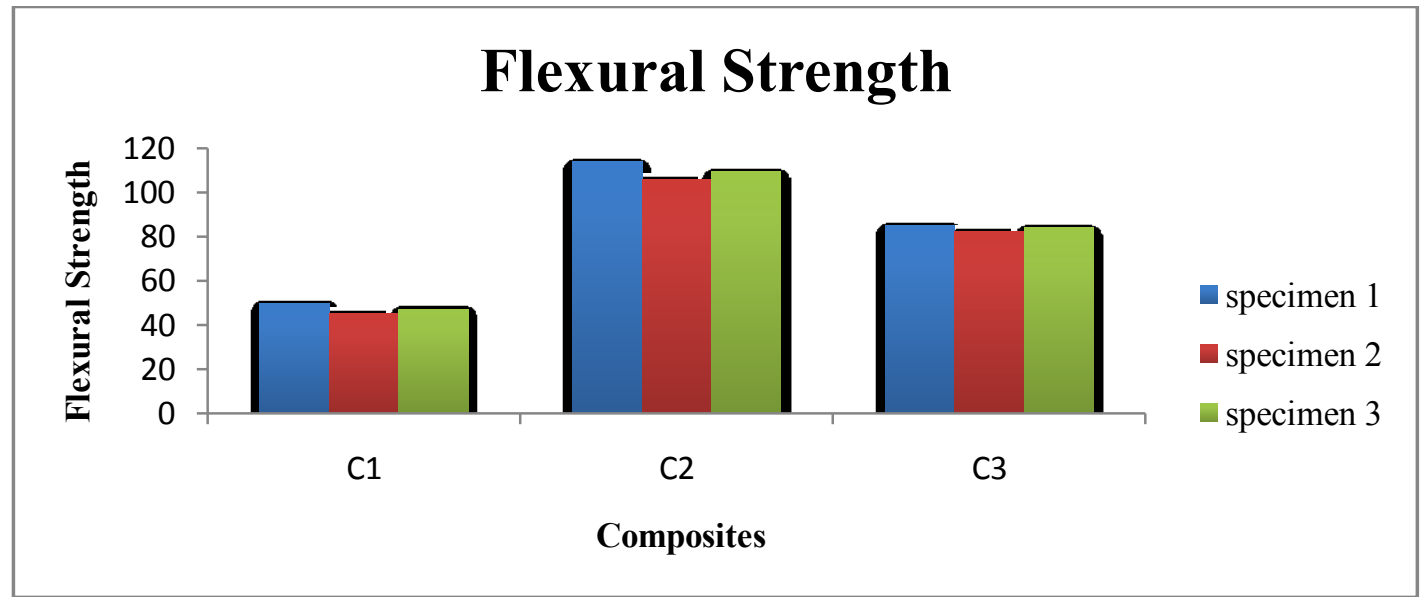

Fig.16 Flexural Strength comparison of different compositions

3.3 Impact Properties: Charpy Impact Test was used to determine the impact properties of the material. The Charpy impact test, also known as the Charpy V-notch test, is a standardized high strain-rate test which determines the amount of energy absorbed by a material during fracture. The fig. 17 shows the Impact Strength comparison of different compositions.

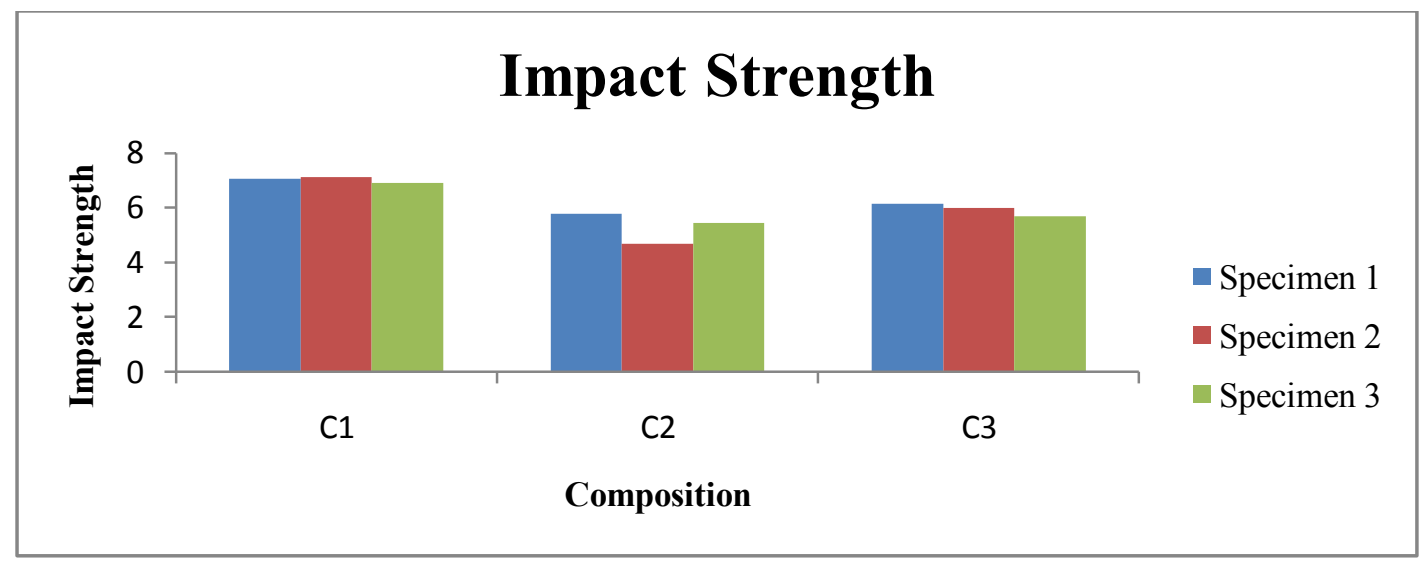

Fig.17 Impact Strength comparison of different compositions 


\section{Conclusion:}

This experimental investigation on Jute - Glass Fiber Reinforced Polyester composites leads to the following conclusions:

$>$ This work shows that successful fabrication of Jute - Glass Fiber Reinforced Polyester composites with different fiber composition is possible by simple hand lay-up technique.

$>$ It has been noticed that the mechanical properties of the composites such as tensile strength, flexural strength, impact strength of the composites are also greatly influenced by the fiber composition.

$>$ In Tensile Test, 50\% GFRP - 50\% Jute composition yielded the highest tensile strength of $84.59 \mathrm{MPa}$.

$>$ In Flexural Test, $60 \%$ GFRP - 40\% Jute composition yielded the highest flexural strength of 113.93 MPa.

$>$ In Impact Test, 50\% GFRP - 50\% Jute composition yielded the highest impact energy of 7.12 Joules.

[1] M.Ramesh, Palanikumar K, Hemachandra Reddy K, Mechanical Property evaluation of sisal-jute-glass Fiber Reinforced Polyester Composites, Composites Part B,vol48 pp.1-9, 2012.

[2] SairaTaj, Munawar Ali Munawar, Shafiullah Khan, Natural fiber-reinforced polymer composites, Received April 2006, accepted March 2007.

[3] Velmurugan R, Manikandan V, Mechanical properties of palmyra/glass fiber hybrid composites, Composites Part a 2007; 38(10):2216-26.

[4] M. Boopalan, M. Niranjana, M.J. Umapathy, Study on the mechanical properties and thermal properties of jute and banana fiber reinforced epoxy hybrid composites, Composites: Part B 51 (2013) 54-57.

[5] Harish, S, D. Peter Michael, A. Bensely, D. Mohan Lal, A. Rajadurai, Mechanical property evaluation of natural fiber coir composite, Materials characterization, vol60, pp.44-49, 2009.

[6] M. Muthuvel, G. Ranganath , K. Janarthananand K. Srinivasan, Characterization Study of Jute and Glass Fiber Reinforced Hybrid Composite Material, International Journal of Engineering Research \& Technology, ISSN: 2278-0181 Vol. 2 Issue 4, April - 2013.

[7] Aleya Fardausy, Md. Alamgir Kabir, Humayun Kabir, M. Mahbubur Rahman, Khadiza Begam, Farid Ahmed, Md. Abul Hossain, Md. Abdul Gafur, Study of physical, mechanical and thermal properties of unidirectional jute fiber reinforced PVC film composites.

[8] T. Munikenche Gowda, A.C.B. Naidu, Rajput Chhaya, Some mechanical properties of untreated jute fabric-reinforced polyester composites, Received 10 December 1997; accepted 1 July 1998.

[9] Carlo Santulli, Mechanical and impact properties of untreated jute fabric reinforced polyester laminates compared with different eglass fibre reinforced laminates.

[10] Mohanty,A.K, Misra, M, Studies on Jute composites - a literature review, Polymer Plastics Technology and Engineering, 34, 729792,1995 .

[11] Roe,P.J. and M.P.Ansell, jute-reinforced polyester composites, J.Mater.Sci., 20;4015,1985.

[12] M Alamgir Kabir, M. Monimul Huque, M. Rabiul Islam, Andrzej k., Bledzki, Treated jute-PP composite, Bio Resources 5(3), $1618-1625,2010$.

[13] Satish Pujari, A. Ramakrishna, M. Suresh Kumar, Comparison of Jute and Banana Fiber Composites: A Review, Accepted 10 January 2014, Available online 01 February 2014, Special Issue-2, 2014.

[14] Venkateshwaran N, ElayaPerumal, A Banana fiber reinforced polymer composites - A review, J Reinf Plast Compos 2010;29:2387-96.

[15] Tara Sen, H. N. Jagannatha Reddy, Application of Sisal, Bamboo, Coir and Jute Natural Composites in Structural Upgradation, International Journal of Innovation, Management and Technology, Vol. 2, No. 3, June 2011.

[16] Amir hossein Esfandiari, Mechanical properties of PP/jute and glass fibres composites: the statistical investigation, Journal of applied sciences 7(24):3943-3950, 2007.

[17] Afroz Mehar, S.Irfan Sadaq, Sameer Mohammed, Experimental Study and the Effect of Alkali Treatment with Time on Jute Polyester Composites, International Journal of Engineering Research, ISSN: 2319-6890, Volume No.2, Issue No.2, pp : 23-21 April 2013.

[18] Amit Bindal, Satnam Singh, N. K. Batra, Rajesh Khanna, Research Article Development of Glass/Jute Fibers Reinforced Polyester Composite, Indian Journal of Materials Science Volume 2013,

[19] D. Dash, S. Samanta, S.S. Gautam, M. Murlidhar. Mechanical Characterizations of Natural Fiber Reinforced Composite Materials, Advanced Materials Manufacturing \& Characterization Vol 3 Issue 1, 2013. 